\title{
Histamine Regulates Molecular Clock Oscillations in Human Retinal Pigment Epithelial Cells via $\mathrm{H}_{1}$ Receptors
}

\author{
Eri Morioka, Yuzuki Kanda, Hayato Koizumi, Tsubasa Miyamoto and Masayuki lkeda* \\ Graduate School of Science and Engineering, University of Toyama, Toyama, Japan
}

Vertebrate eyes are known to contain circadian clocks, but their regulatory mechanisms remain largely unknown. To address this, we used a cell line from human retinal pigment epithelium (hRPE-YC) with stable coexpression of reporters for molecular clock oscillations (Bmal1-luciferase) and intracellular $\mathrm{Ca}^{2+}$ concentrations (YC3.6). We observed concentration-dependent increases in cytosolic $\mathrm{Ca}^{2+}$ concentrations after treatment with

OPEN ACCESS

Edited by:

Arturo Ortega,

Centro de Investigación y de

Estudios Avanzados del Instituto

Politécnico Nacional (CINVESTAV-

IPN), Mexico

Reviewed by:

Anayansi Molina-Hernández,

Instituto Nacional de

Perinatología, Mexico

Jolanta B. Zawilska,

Medical University

of Lodz, Poland

*Correspondence:

Masayuki lkeda

msikeda@sci.u-toyama.ac.jp

Specialty section:

This article was submitted to

Neuroendocrine Science,

a section of the journal

Frontiers in Endocrinology

Received: 29 December 2017 Accepted: 05 March 2018

Published: 19 March 2018

Citation:

Morioka E, Kanda Y, Koizumi H, Miyamoto T and Ikeda M (2018) Histamine Regulates Molecular

Clock Oscillations in Human

Retinal Pigment Epithelial

Cells via $H_{1}$ Receptors.

Front. Endocrinol. 9:108.

doi: 10.3389/fendo.2018.00108 histamine $(1-100 \mu \mathrm{M})$ and complete suppression of histamine-induced $\mathrm{Ca}^{2+}$ mobilizations by $\mathrm{H}_{1}$ histamine receptor $\left(\mathrm{H}_{1} \mathrm{R}\right)$ antagonist $d$-chlorpheniramine $(d-\mathrm{CPA})$ in hRPE-YC cells. Consistently, real-time RT-PCR assays revealed that $H_{1} R$ showed the highest expression among the four subtypes $\left(\mathrm{H}_{1}-\mathrm{H}_{4}\right)$ of histamine receptors in hRPE-YC cells. Stimulation of hRPE-YC cells with histamine transiently increased nuclear localization of phosphorylated $\mathrm{Ca}^{2+} / \mathrm{cAMP}$-response element-binding protein that regulates clock gene transcriptions. Administration of histamine also shifted the Bmal1-/uciferase rhythms with a type-1 phase-response curve, similar to previous results with carbachol stimulations. Treatment of hRPE-YC cells with $d$-CPA or with more specific $\mathrm{H}_{1} \mathrm{R}$ antagonist, ketotifen, blocked the histamine-induced phase shifts. Furthermore, an $\mathrm{H}_{2}$ histamine receptor agonist, amthamine, had little effect on the Bmal1-luciferase rhythms. Although the function of the in vivo histaminergic system within the eye remains obscure, the present results suggest histaminergic control of the molecular clock via $H_{1} R$ in retinal pigment epithelial cells. Also, since $d$-CPA and ketotifen have been widely used (e.g., to treat allergy and inflammation) in our daily life and thus raise a possible cause for circadian rhythm disorders by improper use of antihistamines.

Keywords: antihistamine, cytosolic calcium, human, molecular clock, retina, transcriptional regulation

\section{INTRODUCTION}

The histaminergic system in the central nervous system controls diverse physiological functions including sleeping-waking, thermoregulation, and feeding (1). To achieve these functions, histaminergic neurons in the tuberomammillary nucleus (TMN) of the posterior hypothalamus send long-distance axons into diverse brain areas (2). Interestingly, histaminergic projections from the brain to the retina have been shown to exist in rodents and primates (3-6), but knowledge on

Abbreviations: ANOVA, analysis of variance; CPA, chlorpheniramine; CREB, $\mathrm{Ca}^{2+} / \mathrm{cAMP}^{2}$-response element-binding protein; $\mathrm{CT}$, circadian time; $\mathrm{H}_{1} \mathrm{R}, \mathrm{H}_{1}$ histamine receptor; $\mathrm{H}_{2} \mathrm{R}, \mathrm{H}_{2}$ histamine receptor; $\mathrm{HDC}$, histidine decarboxylase; DAPI, 4',6-diamidino-2-phenylindole; pCREB, phosphorylated CREB; PRC, phase-response curve; RPE, retinal pigment epithelial; SCN, suprachiasmatic nucleus; TMN, tuberomammillary nucleus. 
their physiological functions remains limited. In baboon eyes, histamine reduced flash sensitivity in ON ganglion cells (7). In macaque eyes, $\mathrm{H}_{1}$ histamine receptor $\left(\mathrm{H}_{1} \mathrm{R}\right)$ was expressed in horizontal cells, and $\mathrm{H}_{2}$ histamine receptor $\left(\mathrm{H}_{2} \mathrm{R}\right)$ was expressed in cone photoreceptors (8). Histamine significantly reduced hyperpolarization-activated currents recorded from cones in monkeys (8) and modulated retinal ganglion cell firings in rats and monkeys (9). Furthermore, dopaminergic amacrine cells in mice expressed $\mathrm{H}_{1} \mathrm{R}$ and displayed histamine-induced cytosolic calcium mobilizations (10). Source of histamine within the retina may not be only from the TMN projections but also from local synthesis because genes encoding histamine synthetic enzyme, histidine decarboxylase (HDC), were expressed in the outer nuclear layer of mice retina (11). Meanwhile, no apparent changes in retinal structures and functions were identified in HDC knockout $\left(\mathrm{HDC}^{-/-}\right)$mice (11), and thus retinal histaminergic regulations remain controversial.

Histamine release from histaminergic neurons is generally coupled with vigilance states, being active during wakefulness and inactive during sleep $(1,12)$. Daily rhythms of sleep and wakefulness are strongly regulated by the central circadian pacemaker located within the hypothalamic suprachiasmatic nucleus (SCN; Figure 1A) (13). Meanwhile, SCN neuronal activity rhythms are directly regulated by histaminergic projections $(1,14)$. This suggests the presence of a histaminergic feedback system between the SCN clock and histaminergic sleep-wake mechanisms (Figure 1B). In addition, it is well known that the mammalian retina contains a circadian clock, because rhythmic clock gene expressions have been reported in various retinal cells (15-18). It has also been shown that photoreceptor disk shedding (19-21), dopamine synthesis (22), melatonin release (23), and retinal electrical responses to light (24) are all under circadian clock control. SCN neurons were reported to receive axons from intrinsically photosensitive retinal ganglion cells for photoentrainment of circadian rhythms (25). Thus, it is reasonable to hypothesize that the histaminergic system within the eye may function as an additional feedback system that intermediates between the retinal and central circadian clocks (Figure 1B). However, substantial evidence is lacking to prove this hypothesis. In the earlier works, circadian rhythms in clock gene transcriptional levels and adenylyl cyclase activities were identified in retinal pigment epithelial (RPE) cells (26-28). Based on these findings, a cell line was recently generated from human retinal pigment epithelium, hRPE-YC (29), that stably coexpresses reporters for clock gene transcriptions (Bmal1-luciferase) and intracellular $\mathrm{Ca}^{2+}$ concentrations (YC3.6). Using this model cell line, this study provides evidence for functional expression of $\mathrm{H}_{1} \mathrm{R}$ and histaminergic control of the molecular clock within the eye.

\section{MATERIALS AND METHODS}

\section{Cell Cultures}

hRPE-YC cells (less than five passages) were cultured in Dulbecco's modified Eagle's medium/F12 supplemented with $10 \%$ fetal bovine serum (Invitrogen, Carlsbad, CA, USA), sodium bicarbonate $(1.2 \mathrm{~g} / \mathrm{L})$, and $1 \%$ penicillin/streptomycin antibiotics (Invitrogen) under constant temperature $\left(37^{\circ} \mathrm{C}\right)$ and $5 \% \mathrm{CO}_{2}$.

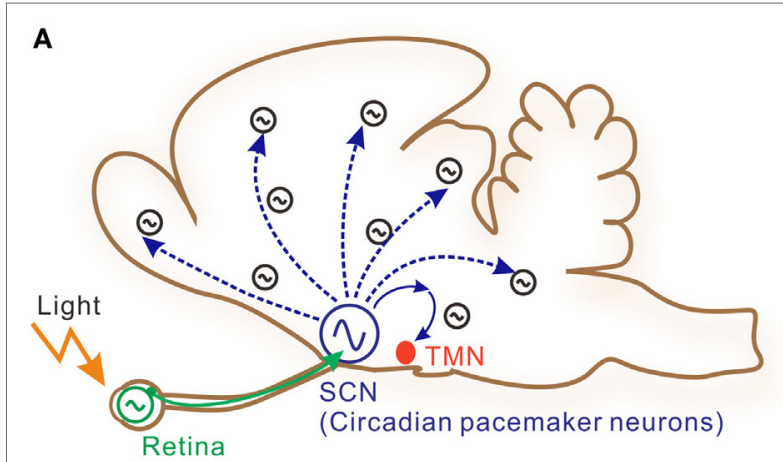

B

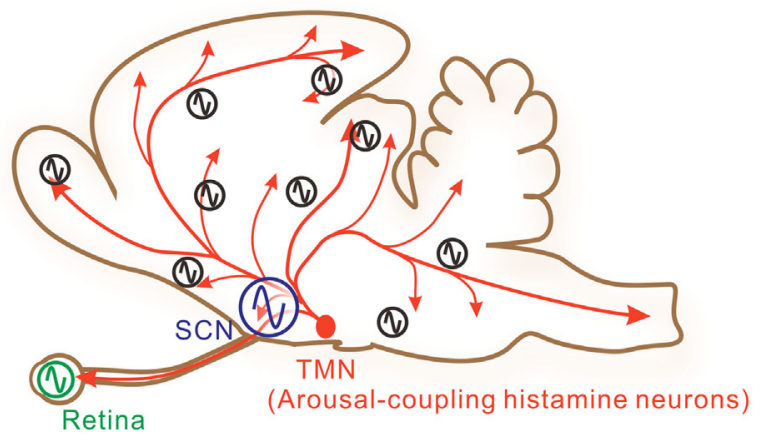

FIGURE 1 | A schematic illustration of interactive signaling underlying photic and histaminergic regulation of the circadian clock. (A) The circadian pacemaker neurons located within the hypothalamic suprachiasmatic nucleus (SCN) are directly controlled by retinal projections (solid green arrow). The retina contains independent circadian oscillators controlling photic sensitivity. Clock gene oscillations are observed in many other cells in the brain, although system-level oscillations are strongly dependent on core SCN oscillations. These peripheral clock oscillations are controlled by indirect neural connections (dashed blue arrows) or humoral factors from the SCN.

The tuberomammillary nucleus (TMN) of the posterior hypothalamus, which contains histamine neurons, may also be under the control of the SCN via hypothalamic neural networks. (B) The TMN sends long-distance axons directly to diverse brain areas and to the retina (solid red arrows). SCN neurons and retinal cells also receive histaminergic fibers and may be under the control of the TMN. Taken together, these features suggest that histaminergic signaling may function as a feedback signal to stabilize or boost system-wide circadian oscillations.

\section{$\mathrm{Ca}^{2+}$ Imaging}

The $\mathrm{Ca}^{2+}$ imaging protocols were described previously (30). Briefly, cells were seeded onto $35-\mathrm{mm}$ glass-bottom dishes. The culture medium was gently rinsed from the dishes using buffered salt solution. Fluorescence images were obtained under perfusion of buffered salt solution using an upright microscope (Axioplan 2; Carl Zeiss, Thornwood, NY, USA) with a water-immersion objective (Achroplan $\times 20 \mathrm{NA} 0.5 \mathrm{w}$; Carl Zeiss). Pairs of fluorescent images $(535 \pm 15 / 480 \pm 15 \mathrm{~nm})$ were produced with a light pulse of $440 \pm 5 \mathrm{~nm}$ generated by a dual filter wheel system (Lambda 10-3; Sutter Instruments, Novato, CA, USA) and acquired using a cooled charge-coupled device camera (CoolSnap Fx; Photometrics, Tucson, AZ, USA). The timings of shutter gating and image acquisitions at 6-s intervals were regulated by digital imaging software (MetaFluor ver. 6.0; Japan Molecular Devices, Tokyo, Japan). Histamine and $d$-chlorpheniramine ( $d$-CPA) 
(both from Sigma-Aldrich, St. Louis, MO, USA) were perfused onto the cells by switching the perfusate.

\section{Bmal1-Luciferase Assay}

The Bmal1-luciferase rhythms were analyzed as described (29) using culture medium supplemented with $50 \mu \mathrm{M}$ beetle luciferin (Promega, Madison, WI, USA) and a multichannel chemiluminescence analyzer (Kronos-Dio, Model AB-2550; ATTO Co. Ltd., Tokyo, Japan) set at $37^{\circ} \mathrm{C}$. The time point with the peak chemiluminescence level in the Bmal1-luciferase rhythms was regarded as circadian time (CT) 20. To analyze phaseresponse curves (PRCs) against pharmacological stimulations, Kronos recordings were paused for $5 \mathrm{~min}$. During the pause, $10 \%$ of culture medium $(100 \mu \mathrm{L})$ was collected from each dish. Histamine, amthamine dihydrobromide, ketotifen fumarate (Sigma-Aldrich), or $d$-CPA was added to the collected culture medium and gently returned to the culture dish (final diluted concentration: $50 \mu \mathrm{M}$ for histamine, $50 \mu \mathrm{M}$ for amthamine dihydrobromide, $10 \mu \mathrm{M}$ for $d$-CPA, and $10 \mu \mathrm{M}$ for ketotifen). Although hRPE-YC cells represented little sensitivity to light (29), above medium exchanges were carefully conducted under dim red light $(<3 \mathrm{~lx})$. The PRCs were eye fitted by three experienced investigators.

\section{Immunofluorescence Confocal Imaging}

To examine the effects of histamine on the phosphorylation levels of $\mathrm{Ca}^{2+} / \mathrm{cAMP}$ response element-binding protein (CREB), hRPE-YC cells plated on 35-mm glass-bottom dishes were stimulated with histamine $(100 \mu \mathrm{M})$ for 10 min during subjective night-time. Immediately after the stimulations, hRPE-YC cells were fixed in $4 \%$ phosphate-buffered paraformaldehyde for $15 \mathrm{~min}$ and washed three times with phosphate-buffered saline. The samples were immunostained with 1:100 diluted affinity-purified rabbit anti-P-CREB (pSer ${ }^{133}$ ) (Sigma-Aldrich) and embedded in Vectashield (Vector Laboratories, Burlingame, CA, USA) containing 4',6-diamidino-2-phenylindole (DAPI) as described (29). Images were acquired using a confocal laserscanning microscope (A1MP plus; Nikon, Tokyo, Japan).

\section{Real-Time RT-PCR Assay}

The mRNAs for the four histamine receptor subtypes $\left(\mathrm{H}_{1}-\mathrm{H}_{4}\right)$ and HDC were quantified by referring a housekeeping gene (human $\beta$-actin) in hRPE-YC cells using a real-time RT-PCR system (Roter-Gene Ver. 6.0 software, Corbett Research, Sydney, NSW, Australia). The cell cultures and RNA extraction procedures were described previously (29). The PCR primers for histamine receptors (31) and HDC (32) were designed elsewhere. Each primer $(100 \mu \mathrm{M})$ was used with Rotor-Gene SYBR Green RT-PCR Master Mix (Qiagen, Germantown, MD, USA) in the 72-well rotor of the PCR system (Rotor Gene 3000A; Corbett Research) as described (29). mRNA levels were expressed as $2^{-\Delta C t}$ using $\beta$-actin mRNA level as internal standard.

\section{Statistical Analysis}

Data are presented as mean \pm SEM. One-way analysis of variance followed by Duncan's multiple range test and four-parameter Hill function were used to analyze concentration-response curve for histamine. Kruskal-Wallis test followed by SteelDwass test was used to compare gene expression profiles. A two-tailed Student's $t$-test was used for pairwise comparisons. A 95\% confidence level was considered to indicate statistical significance.

\section{RESULTS}

Histamine mobilized intracellular $\mathrm{Ca}^{2+}$ in hRPE-YC cells in a concentration-dependent manner with an $\mathrm{EC}_{50}$ value of $10.4 \mu \mathrm{M}$ (Figures 2A-C). At $100 \mu \mathrm{M}$, histamine consistently evoked a $\mathrm{Ca}^{2+}$ response in nearly all cells tested $(97 \pm 1.4 \%$; 397 of 410 cells in 18 dishes). The histamine-induced $\mathrm{Ca}^{2+}$ response was significantly inhibited by pretreatment with $10 \mu \mathrm{M} d$-CPA (Figure 2B), suggesting that the response was primarily mediated by $\mathrm{H}_{1} \mathrm{R}$. Intracellular $\mathrm{Ca}^{2+}$ mobilizations after continuous bath application of $50 \mu \mathrm{M}$ histamine were also examined, because this application was used for the Bmal1-luciferase assays. Bath application of $50 \mu \mathrm{M}$ histamine produced a transient $\mathrm{Ca}^{2+}$ response that almost recovered to the baseline during a 30-min exposure period (Figure 2D).

To characterize the histamine receptor subtypes $\left(\mathrm{H}_{1}-\mathrm{H}_{4}\right)$ expressed in hRPE-YC cells, cells were collected for real-time RT-PCR assays at early subjective daytime (CT1-CT3; number of dishes $=7$ ) and early subjective night-time (CT13-CT15; number of dishes $=4$ ) following on-line monitoring of the Bmal1-luciferase rhythms. The results revealed that $\mathrm{H}_{1} \mathrm{R}$ showed the highest expression among the four histamine receptor subtypes with no difference in the levels between subjective daytime and subjective night-time. The expression levels of $\mathrm{H}_{3}$ and $\mathrm{H}_{4}$ histamine receptors were near to the detection limits. Therefore, the gene expression levels were further analyzed regardless of sampling time using a non-parametric test (Figure 3). The expression levels of $\mathrm{H}_{1} \mathrm{R}(P<0.01)$ and $\mathrm{H}_{2} \mathrm{R}(P<0.05)$ were significantly larger than those of $\mathrm{H}_{3}$ and $\mathrm{H}_{4}$ histamine receptors (Kruskal-Wallis test followed by Steel-Dwass test). In addition to these analyses, capability of histamine synthesis in hRPE-YC cells was analyzed by monitoring HDC expression. However, HDC expression was negligible in these cells (Figure 3).

To estimate the gene transcriptional regulations by histamine, immunofluorescence staining of phosphorylated CREB (pCREB) in hRPE-YC cells after histamine stimulation was examined. Compared with unstimulated controls (optical density $=31 \pm 0.2$, number of cells $=328$, number of dishes $=3$ ), treatment with $50 \mu \mathrm{M}$ histamine for $10 \mathrm{~min}$ doubled the pCREB staining levels in the nucleus (optical density $=65.5 \pm 1.9$, number of cells $=312$, number of dishes $=3$; Figure 4 ). Consistent with the nuclear pCREB inductions, the same histamine stimulation produced circadian phase-delays or advances in the Bmal1-luciferase rhythms (Figure 5A). Accordingly, the type-1 PRC was eye fitted on the phase-shifting profiles dependent on the CT (Figure 5B). The histamine-induced phase shifts at CT14 $(-2.8 \pm 0.6 \mathrm{~h}$, number of dishes $=5$ in histamine-stimulated group) and CT20 $(+5.4 \pm 0.5 \mathrm{~h}$, number of dishes $=6$ in histamine-stimulated group) were almost completely inhibited by $d$-CPA or ketotifen treatment (Figure 5B). Compared with the phase responses to histamine stimulations, the $\mathrm{H}_{2} \mathrm{R}$-specific 

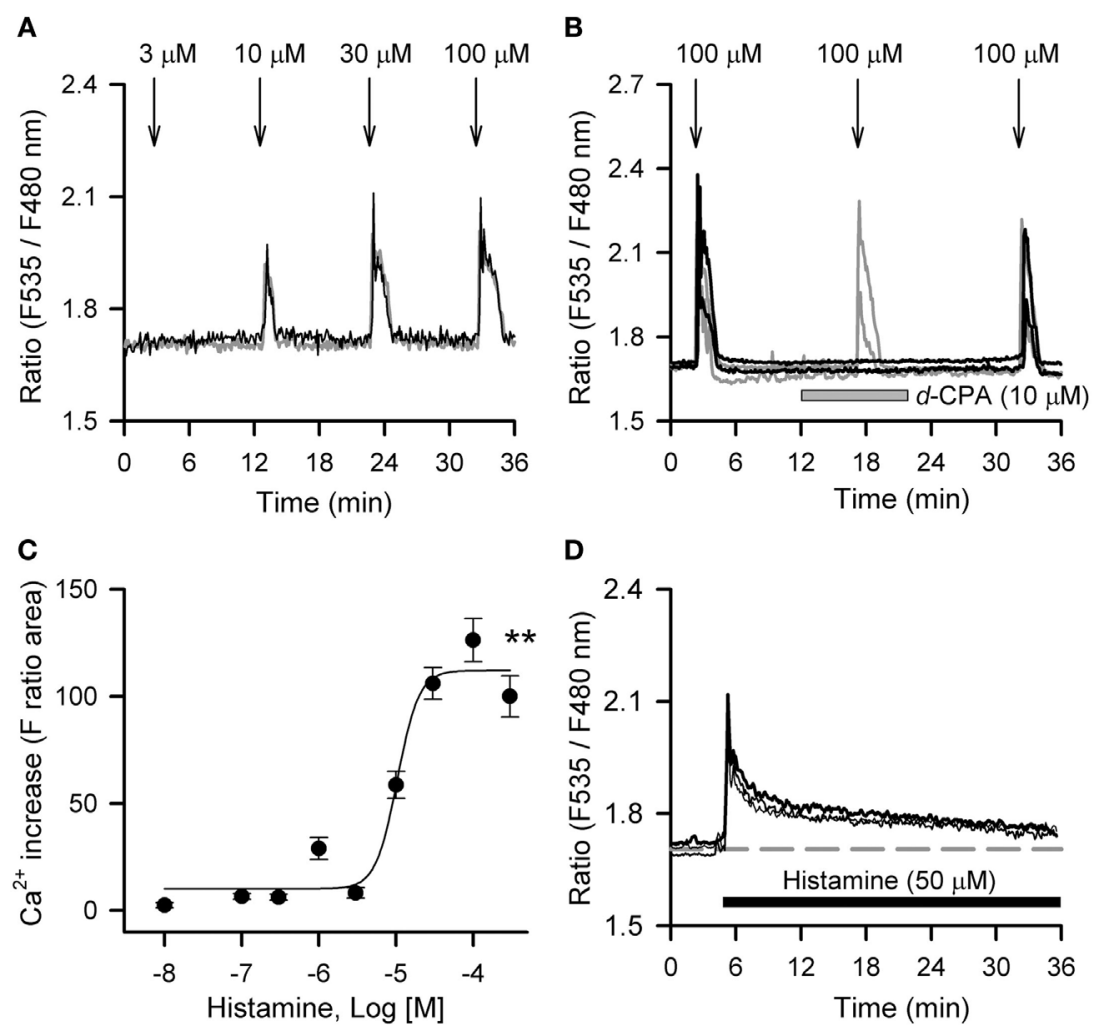

FIGURE 2 | Histamine-induced calcium mobilizations in hRPE-YC cells. (A) Histamine (3-100 $\mu$ M) evoked dose-dependent increases in cytosolic Ca ${ }^{2+}$ concentrations in hRPE-YC cells. Two representative cell responses are shown. Arrows denote the onsets of 1-min histamine stimulations. (B) Repeated 100- $\mu \mathrm{M}$ histamine stimulations with 15-min intervals consistently elevated cytosolic $\mathrm{Ca}^{2+}$ in hRPE-YC cells (gray traces). In this experiment, the second histamine stimulation was also examined under perfusion of $10 \mu \mathrm{M} d$-chlorpheniramine ( $d$-CPA) (black traces). Note that complete inhibition of Ca ${ }^{2+}$ responses by $d$-CPA and recovery of $\mathrm{Ca}^{2+}$ responses after rinsing out of $d$-CPA were observed. All of the above experiments were reproducible in at least three independent trials in separate culture dishes. (C) Concentration-response curves for histamine. ${ }^{\star \star} P<0.01$ by one-way analysis of variance. (D) Continuous perfusion of histamine (50 $\mu \mathrm{M}$, black bar) mobilized $\mathrm{Ca}^{2+}$ depending on the onset of stimulations without further amplification of $\mathrm{Ca}^{2+}$ responses during stimulations. The gray dashed line denotes the mean baseline $\mathrm{Ca}^{2+}$ level in the three representative cells.

agonist amthamine $(50 \mu \mathrm{M})$ produced smaller phase delays (18.6\% of histamine responses, $P<0.01$ by Student's $t$-test, number of dishes $=3$ at CT16) and phase advances $(10.3 \%$ of histamine responses, $P<0.01$ by Student's $t$-test, number of dishes $=3$ at CT20; Figure 5B).

\section{DISCUSSION}

In this study, we explored the functions of histamine signaling in RPE cells using a human cell line. The results for $\mathrm{Ca}^{2+}$ imaging and real-time RT-PCR clearly demonstrated functional expression of $\mathrm{H}_{1} \mathrm{R}$ in hRPE-YC cells. As $\mathrm{H}_{1} \mathrm{R}$ couples with $\mathrm{G}_{\mathrm{q}}$ proteins and links with the phosphatidylinositol signaling pathway to mobilize cytosolic $\mathrm{Ca}^{2+}$, the conventional intracellular signaling pathway reported for RPE cells $(33,34)$ could be the trigger for phase shifts of Bmal1 transcriptional rhythms. Indeed, nuclear pCREB expression was observed following the histamine stimulations. These results are consistent with a previous finding that stimulation of $\mathrm{G}_{\mathrm{q}}$-coupled $M 3$ muscarinic acetylcholine receptors in hRPE-YC cells resulted in transient $\mathrm{Ca}^{2+}$ increases, nuclear pCREB expressions, and phase shifts of
Bmal1-luciferase rhythms with a type-1 PRC (29). Meanwhile, this study indicated gene expression of $\mathrm{G}_{\mathrm{s}}$-coupled $\mathrm{H}_{2} \mathrm{R}$ in hRPE-YC cells but failed to demonstrate apparent phase shifts of Bmal1-luciferase rhythms by amthamine. In the previous study, forskolin, a pharmacological activator of adenylate cyclase, produced apparent phase shifts in hRPE-YC cells (29). Taken together, it is suggested that functional $\mathrm{H}_{2} \mathrm{R}$ expression and activation of the downstream adenylate cyclase pathway could be limited in hRPE-YC cells. Histamine-induced circadian phase shifts have been studied in SCN slice preparations by reference to action potential firing rhythms (14), and this study indicates that similar histaminergic regulations may be present in the retinal circadian clock.

Retinal pigment epithelial cells have multiple functions within the retina. Among these, it should be emphasized that RPE cells are involved in the daily photoreceptor disk shedding critical for circadian rhythms in photic sensitivities. Phagocytosis of the photoreceptor outer segment by RPE cells is directly triggered by light or by intrinsic circadian clock mechanisms given that the rhythm is sustained under constant darkness (21). Although innervations from central histaminergic neurons have been 


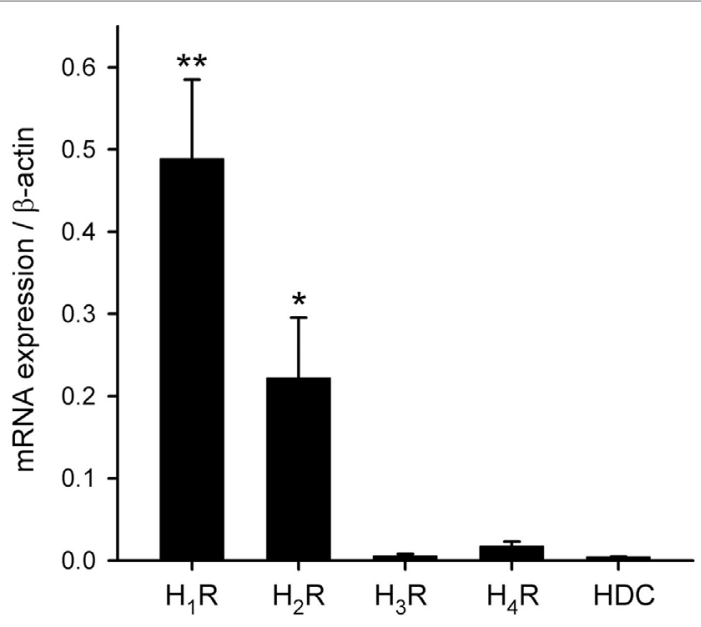

FIGURE 3 | Transcriptional profiles of histamine receptor subtypes and histamine synthetic enzyme. $\mathrm{H}_{1}-\mathrm{H}_{4} \mathrm{Rs}$ and histidine decarboxylase (HDC) mRNAs were quantified in hRPE-YC cells by quantitative RT-PCR with $2^{-\Delta C t}$ using $\beta$-actin as internal control. $H_{1}$ histamine receptor $\left(H_{1} R\right)$ exhibited the highest expression among the four subtypes. There were also detectable levels of $\mathrm{H}_{2}$ histamine receptor $\left(\mathrm{H}_{2} \mathrm{R}\right)$ expression in these cells. HDC was not expressed in hRPE-YC cells. ${ }^{\star \star} P<0.01$ and ${ }^{\star} P<0.05$ by Kruskal-Wallis test followed by Steel-Dwass test. Data represent mean \pm SEM from 11 dishes.

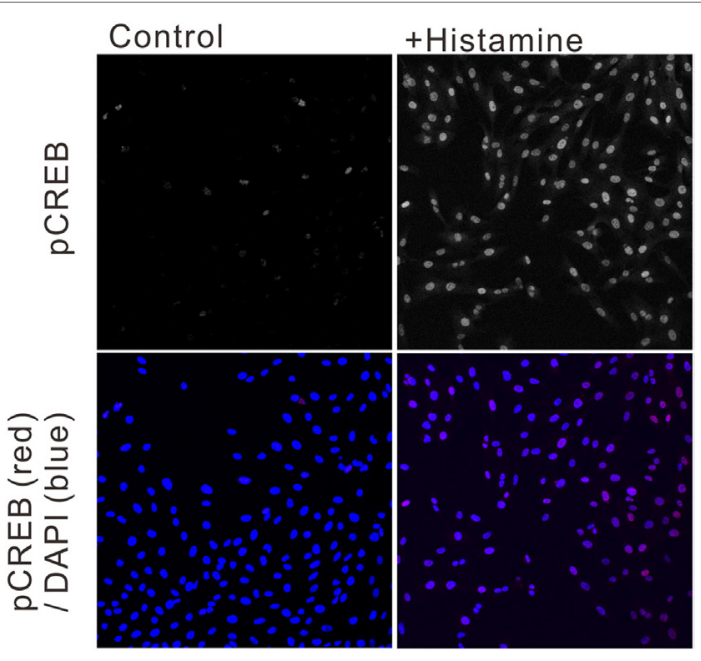

FIGURE 4 | $\mathrm{Ca}^{2+} / \mathrm{CAMP}-$ response element-binding protein phosphorylation following histamine exposure. Immunofluorescence staining of phosphorylated CREB (pCREB) in unstimulated control hRPE-YC cells (left two images) and hRPE-YC cells after exposure to $50 \mu \mathrm{M}$ histamine for 10 min (right two images). Counter-staining with 4',6-diamidino-2phenylindole (blue color in merged picture) demonstrated the nuclear localization of pCREB signals in hRPE-YC cells following the histamine stimulation.

identified primarily in the ganglion cell layer and inner plexiform layer in the retina (4-9), histamine could be a paracrine modulator for various retinal cells. In addition, it has shown that the outer nuclear layer of mice retina express HDC genes using a laser microdissection technique (11), although the type of retinal cells synthesizing histamine has not yet been characterized.
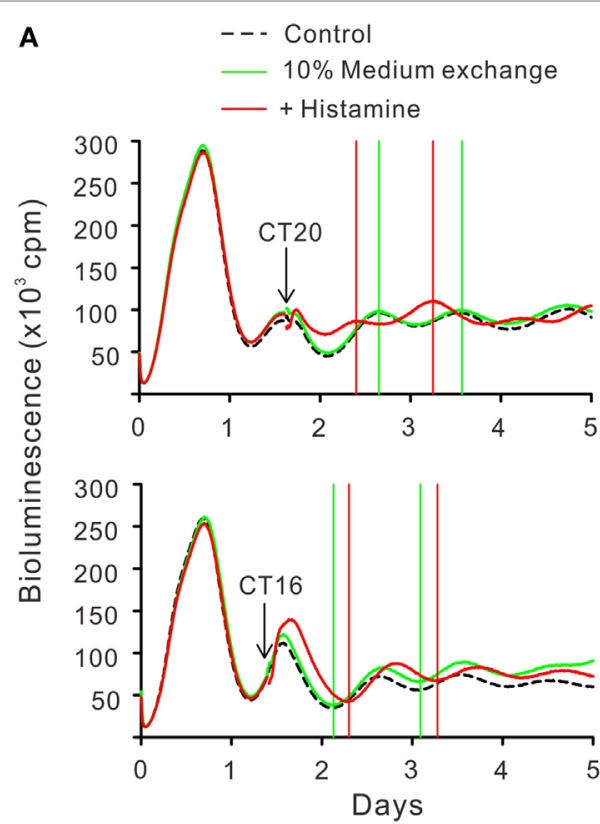

B

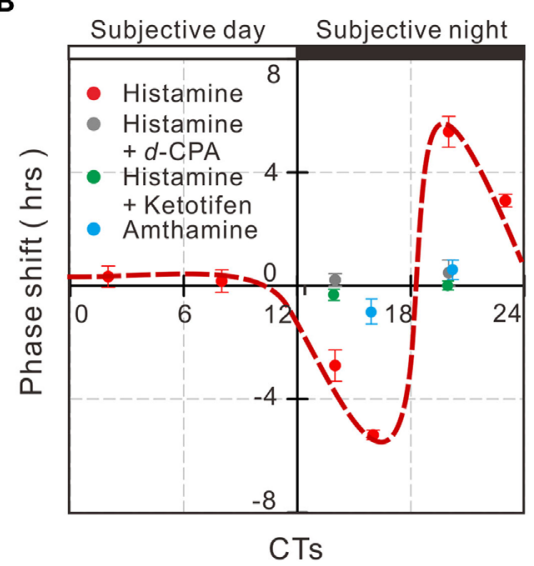

FIGURE 5 | Circadian phase shifts in Bmal1 transcriptional rhythms following histamine exposure. (A) The mean Bmal1-luciferase intensities in 35-mm dishes were quantified using a multichannel chemiluminescence analyzer. The arrows indicate onset of $50 \mu \mathrm{M}$ histamine exposures at CT20 and CT16. Subsequent troughs or peaks of circadian waves were compared with groups of non-treated control cells. (B) Based on the histamine-induced phase shifts at various time points, a type-1 phase-response curve was eye fitted (red circles with dotted line). Similar stimulation of cells by the $\mathrm{H}_{2}$ histamine receptor agonist amthamine at CT20 or CT16 produced significantly smaller phase shifts (blue circles). Treatment with $10 \mu \mathrm{M}$ $d$-chlorpheniramine (d-CPA) or ketotifen almost completely abolished the histamine-induced phase-advances at CT20 and delays at CT14 (gray circles for $d$-CPA treatment and green circles for ketotifen treatment). Data represent mean \pm SEM from three to six dishes.

Thus, it is possible that histaminergic control of RPE cells, if any in in vivo, could be involved in the regulation of photoreceptor disk shedding rhythms. It was also shown that $\mathrm{HDC}^{-/-}$mice with recovery of the Crb1 mutation exhibit normal retinal structures and functions, including the outer segment (11). However, these analyses were conducted under 12 -h/12-h light/dark cycles and paid no particular attention to the tissue sampling time. Under 
these circumstances, the direct light information was presumably sufficient to determine the phenotypes. Histamine release from histaminergic neurons is coupled with sleep-wake states $(1,12)$. Importantly, significant reductions in clock gene (Per1 and Per2) transcriptional rhythms have been shown in many brain regions outside the SCN in $\mathrm{HDC}^{-/-}$mice (35). This suggests remote control of peripheral clock gene transcriptional rhythms by the brain histaminergic system (Figure 1). Thus, it is of particular interest whether changes in histaminergic tones and sleep-wake status can exert feedback on retinal clock regulations and ultimately on circadian clock systems. Further studies are needed to clarify these possibilities.

In relation to the effect of the $\mathrm{H}_{1} \mathrm{R}$ antagonist observed in this study, we would like to emphasize the possible influence on human circadian clock regulations because $\mathrm{H}_{1} \mathrm{R}$ antagonists are widely used in daily life. First-generation $\mathrm{H}_{1} \mathrm{R}$ antagonists, such as $d$-CPA, are permeable to the brain and induce sedation and/or slow-wave sleep following systemic administration in rats $(36,37)$. Based on these effects, one of the first-generation $\mathrm{H}_{1} \mathrm{R}$ antagonists, diphenhydramine, is currently sold as a sleeping aid in Japan. In addition, doxepin, another first-generation $\mathrm{H}_{1} \mathrm{R}$ antagonist known to induce sleep, has been approved by the FDA for treatment of insomnia in the United States (38). Furthermore, numerous $\mathrm{H}_{1} \mathrm{R}$ antagonists are currently sold as eye drops to treat ocular allergies (39). Despite the widespread use of $H_{1} R$ antagonists, their influence on circadian clock regulations has not been analyzed in detail. The effects of daily systemic injections of ketotifen (an early phase second-generation $\mathrm{H}_{1} \mathrm{R}$ antagonist) were recently evaluated in rats, with significant effects observed on their circadian locomotor activity rhythms (40). In addition, we preliminary observed reduction in Per 2 transcriptional rhythms in the SCN and hippocampus by daily systemic injections of ketotifen in rats (unpublished data). Numerous antihistamines,

\section{REFERENCES}

1. Haas HL, Sergeeva OA, Selbach O. Histamine in the nervous system. Physiol $\operatorname{Rev}(2008)$ 88(3):1183-241. doi:10.1152/physrev.00043.2007

2. Inagaki $\mathrm{N}$, Yamatodani $\mathrm{A}$, Ando-Yamamoto $\mathrm{M}$, Tohyama $\mathrm{M}$, Watanabe $\mathrm{T}$, Wada H. Organization of histaminergic fibers in the rat brain. J Comp Neurol (1988) 273(3):283-300. doi:10.1002/cne.902730302

3. Airaksinen MS, Panula P. The histaminergic system in the guinea pig central nervous system: an immunocytochemical mapping study using an antiserum against histamine. J Comp Neurol (1988) 273(2):163-86. doi:10.1002/ cne.902730204

4. Gastinger MJ, O’Brien JJ, Larsen NB, Marshak DW. Histamine immunoreactive axons in the macaque retina. Invest Ophthalmol Vis Sci (1999) 40(2):487-95.

5. Gastinger MJ, Tian N, Horvath T, Marshak DW. Retinopetal axons in mammals: emphasis on histamine and serotonin. Curr Eye Res (2006) 31(7-8):655-67. doi:10.1080/02713680600776119

6. Greferath U, Kambourakis M, Barth C, Fletcher EL, Murphy M. Characterization of histamine projections and their potential cellular targets in the mouse retina. Neuroscience (2009) 158(2):932-44. doi:10.1016/j. neuroscience.2008.10.034

7. Akimov NP, Marshak DW, Frishman LJ, Glickman RD, Yusupov RG. Histamine reduces flash sensitivity of on ganglion cells in the primate retina. Invest Ophthalmol Vis Sci (2010) 51(7):3825-34. doi:10.1167/iovs.09-4806

8. Vila A, Satoh H, Rangel C, Mills SL, Hoshi H, O'Brien J, et al. Histamine receptors of cones and horizontal cells in Old World monkey retinas. J Comp Neurol (2012) 520(3):528-43. doi:10.1002/cne.22731 including $d$-CPA and ketotifen, represent affinity to muscarinic receptors to block acetylcholine signaling $(41,42)$ and thus use of antihistamines especially at high doses may also exert their influence on cholinergic clock regulations $(29,43)$. Together with the present results showing complete suppression of histamineinduced circadian phase shifts in hRPE-YC cells by $d$-CPA or ketotifen, we suggest that further clinical studies to analyze the influence of antihistamines on human circadian rhythms, with a special focus on circadian visual functions, are warranted.

In conclusion, the present results suggest histaminergic control of the molecular clock via $\mathrm{H}_{1} \mathrm{R}$ in a model cell line for human RPE cells and thus raise a possible cause for circadian rhythm disorders by daily use of antihistamines.

\section{AUTHOR CONTRIBUTIONS}

MI designed the study, wrote and edited the manuscript, and directed the project. EM, YK, HK, and TM performed the experiments. EM analyzed the data.

\section{ACKNOWLEDGMENTS}

The authors are grateful to Yuuka Kobayashi, Risako Nakai, Rina Ikarashi, and Honami Akechi for their elegant technical assistance.

\section{FUNDING}

This work was supported in part by a Grant-in-Aid for Scientific Research (grant number: 16H04651) from the Ministry of Education, Culture, Sports, Science, and Technology, Japan, to $\mathrm{EM}$ and $\mathrm{MI}$ and a special coordination fund from the president of Toyama University to EM.

9. Gastinger MJ, Yusupov RG, Glickman RD, Marshak DW. The effects of histamine on rat and monkey retinal ganglion cells. Vis Neurosci (2004) 21(6):935-43. doi:10.1017/S0952523804216133

10. Frazão R, McMahon DG, Schunack W, Datta P, Heidelberger R, Marshak DW. Histamine elevates free intracellular calcium in mouse retinal dopaminergic cells via $\mathrm{H}_{1}$-receptors. Invest Ophthalmol Vis Sci (2011) 52(6):3083-8. doi:10.1167/iovs.10-6160

11. Greferath U, Vessey KA, Jobling AI, Mills SA, Bui BV, He Z, et al. The role of histamine in the retina: studies on the Hdc knockout mouse. PLoS One (2014) 9(12):e116025. doi:10.1371/journal.pone.0116025

12. Mochizuki T, Yamatodani A, Okakura K, Horii A, Inagaki N, Wada H. Circadian rhythm of histamine release from the hypothalamus of freely moving rats. Physiol Behav (1992) 51(2):391-4. doi:10.1016/0031-9384 (92)90157-W

13. Edgar DM, Dement WC, Fuller CA. Effect of SCN lesions on sleep in squirrel monkeys: evidence for opponent processes in sleep-wake regulation. J Neurosci (1993) 13(3):1065-79.

14. Cote NK, Harrington ME. Histamine phase shifts the circadian clock in a manner similar to light. Brain Res (1993) 613(1):149-51. doi:10.1016/ 0006-8993(93)90465-Y

15. Ruan GX, Zhang DQ, Zhou T, Yamazaki S, McMahon DG. Circadian organization of the mammalian retina. Proc Natl Acad Sci U S A (2006) 103(25):9703-8. doi:10.1073/pnas.0601940103

16. Baba K, Sengupta A, Tosini M, Contreras-Alcantara S, Tosini G. Circadian regulation of the PERIOD 2:LUCIFERASE bioluminescence rhythm in the mouse retinal pigment epithelium-choroid. Mol Vis (2010) 16:2605-11. 
17. Liu X, Zhang Z, Ribelayga CP. Heterogeneous expression of the core circadian clock proteins among neuronal cell types in mouse retina. PLoS One (2012) 7(11):e50602. doi:10.1371/journal.pone.0050602

18. Xu L, Ruan G, Dai H, Liu AC, Penn J, McMahon DG. Mammalian retinal Müller cells have circadian clock function. Mol Vis (2016) 22:275-83.

19. LaVail MM. Rod outer segment disk shedding in rat retina: relationship to cyclic lighting. Science (1976) 194(4269):1071-4. doi:10.1126/science.982063

20. Terman JS, Remé CE, Terman M. Rod outer segment disk shedding in rats with lesions of the suprachiasmatic nucleus. Brain Res (1993) 605(2):256-64. doi:10.1016/0006-8993(93)91748-H

21. Grace MS, Wang LM, Pickard GE, Besharse JC, Menaker M. The tau mutation shortens the period of rhythmic photoreceptor outer segment disk shedding in the hamster. Brain Res (1996) 735(1):93-100. doi:10.1016/00068993(96)00600-2

22. Doyle SE, McIvor WE, Menaker M. Circadian rhythmicity in dopamine content of mammalian retina: role of the photoreceptors. J Neurochem (2002) 83(1):211-9. doi:10.1046/j.1471-4159.2002.01149.x

23. Tosini G, Menaker M. Circadian rhythms in cultured mammalian retina. Science (1996) 272(5260):419-21. doi:10.1126/science.272.5260.419

24. Manglapus MK, Uchiyama H, Buelow NF, Barlow RB. Circadian rhythms of rod-cone dominance in the Japanese quail retina. J Neurosci (1998) 18(12):4775-84.

25. Chen SK, Badea TC, Hattar S. Photoentrainment and pupillary light reflex are mediated by distinct populations of ipRGCs. Nature (2011) 476(7358):92-5. doi:10.1038/nature10206

26. Pavan B, Frigato E, Pozzati S, Prasad PD, Bertolucci C, Biondi C. Circadian clocks regulate adenylyl cyclase activity rhythms in human RPE cells. Biochem Biophys Res Commun (2006) 350(1):169-73. doi:10.1016/j.bbrc.2006.09.015

27. Yoshikawa A, Shimada H, Numazawa K, Sasaki T, Ikeda M, Kawashima M, et al. Establishment of human cell lines showing circadian rhythms of bioluminescence. Neurosci Lett (2008) 446(1):40-4. doi:10.1016/j.neulet. 2008.08.091

28. Baba K, DeBruyne JP, Tosini G. Dopamine 2 receptor activation entrains circadian clocks in mouse retinal pigment epithelium. Sci Rep (2017) 7(1):5103. doi:10.1038/s41598-017-05394-X

29. Ikarashi R, Akechi H, Kanda Y, Ahmad A, Takeuchi K, Morioka E, et al. Regulation of molecular clock oscillations and phagocytic activity via muscarinic $\mathrm{Ca}^{2+}$ signaling in human retinal pigment epithelial cells. Sci Rep (2017) 7:44175. doi:10.1038/srep44175

30. Takeuchi K, Mohammad S, Ozaki T, Morioka E, Kawaguchi K, Kim J, et al. Serotonin-2C receptor involved serotonin-induced $\mathrm{Ca}^{2+}$ mobilisations in neuronal progenitors and neurons in rat suprachiasmatic nucleus. Sci Rep (2014) 4:4106. doi:10.1038/srep04106

31. Müller T, Myrtek D, Bayer H, Sorichter S, Schneider K, Zissel G, et al. Functional characterization of histamine receptor subtypes in a human bronchial epithelial cell line. Int J Mol Med (2006) 18(5):925-31. doi:10.3892/ ijmm.18.5.925

32. Mizuguchi H, Das AK, Maeyama K, Dev S, Shahriar M, Kitamura Y, et al. Antihistamines suppress upregulation of histidine decarboxylase gene expression with potencies different from their binding affinities for histamine $\mathrm{H}_{1}$ receptor in toluene 2,4-diisocyanate-sensitized rats. J Pharmacol Sci (2016) 130(4):212-8. doi:10.1016/j.jphs.2016.02.002
33. Feldman EL, Randolph AE, Johnston GC, DelMonte MA, Greene DA. Receptor-coupled phosphoinositide hydrolysis in human retinal pigment epithelium. J Neurochem (1991) 56(6):2094-100. doi:10.1111/j.1471-4159. 1991.tb03471.x

34. Stalmans $\mathrm{P}$, Himpens $\mathrm{B}$. Confocal imaging of $\mathrm{Ca}^{2+}$ signaling in cultured rat retinal pigment epithelial cells during mechanical and pharmacologic stimulation. Invest Ophthalmol Vis Sci (1997) 38(1):176-87.

35. Abe H, Honma S, Ohtsu H, Honma K. Circadian rhythms in behavior and clock gene expressions in the brain of mice lacking histidine decarboxylase. Brain Res Mol Brain Res (2004) 124(2):178-87. doi:10.1016/j. molbrainres.2004.02.015

36. Ikeda-Sagara M, Ozaki T, Shahid M, Morioka E, Wada K, Honda K, et al. Induction of prolonged, continuous slow-wave sleep by blocking cerebral $\mathrm{H}_{1}$ histamine receptors in rats. Br J Pharmacol (2012) 165(1):167-82. doi:10.1111/j.1476-5381.2011.01547.x

37. Unno K, Ozaki T, Mohammad S, Tsuno S, Ikeda-Sagara M, Honda K, et al. First and second generation $\mathrm{H} 1$ histamine receptor antagonists produce different sleep-inducing profiles in rats. Eur J Pharmacol (2012) 683(1-3):179-85. doi:10.1016/j.ejphar.2012.03.017

38. Yeung WF, Chung KF, Yung KP, Ng TH. Doxepin for insomnia: a systematic review of randomized placebo-controlled trials. Sleep Med Rev (2015) 19:75-83. doi:10.1016/j.smrv.2014.06.001

39. Friedlaender M. Overview of ocular allergy treatment. Curr Allergy Asthma Rep (2001) 1(4):375-9. doi:10.1007/s11882-001-0051-1

40. Ahmad A, Takeuchi K, Ozaki T, Unno K, Mohammad S, Akechi H, et al. Possible treatment of circadian sleep disorders using daily ketotifen administration. Sleep Biol Rhythms (2016) 14(1):117-20. doi:10.1007/s41105015-0021-y

41. Eltze M, Mutschler E, Lambrecht G. Affinity profiles of pizotifen, ketotifen and other tricyclic antimuscarinics at muscarinic receptor subtypes M1, M2 and M3. Eur J Pharmacol (1992) 211(3):283-93. doi:10.1016/00142999(92)90383-F

42. Yasuda SU, Yasuda RP. Affinities of brompheniramine, chlorpheniramine, and terfenadine at the five human muscarinic cholinergic receptor subtypes. Pharmacotherapy (1999) 19(4):447-51. doi:10.1592/phco.19.6. 447.31041

43. Liu C, Ding JM, Faiman LE, Gillette MU. Coupling of muscarinic cholinergic receptors and cGMP in nocturnal regulation of the suprachiasmatic circadian clock. J Neurosci (1997) 17(2):659-66.

Conflict of Interest Statement: The authors declare that the research was conducted in the absence of any commercial or financial relationships that could be construed as a potential conflict of interest.

Copyright (c) 2018 Morioka, Kanda, Koizumi, Miyamoto and Ikeda. This is an open-access article distributed under the terms of the Creative Commons Attribution License (CC BY). The use, distribution or reproduction in other forums is permitted, provided the original author(s) and the copyright owner are credited and that the original publication in this journal is cited, in accordance with accepted academic practice. No use, distribution or reproduction is permitted which does not comply with these terms. 